\title{
Evidence for supporting cell mitosis in response to acoustic trauma in the avian inner ear
}

\author{
Y. RAPHAEL \\ Kresge Hearing Research Institute, The University of Michigan, 1301 East Ann Street, Ann Arbor, Michigan 48109, USA
}

Received 27 January 1992; revised 24 April 1992; accepted 5 May 1992

\begin{abstract}
Summary
Acoustic overstimulation can lead to sensory cell (hair cell) loss in the auditory epithelium. Damaged hair cells in the organ of Corti (the mammalian auditory end-organ) degenerate and are replaced by non-sensory cells (supporting cells) which construct an irreversible scar. In birds, however, auditory hair cells which are damaged by acoustic trauma or ototoxic drugs may be replaced by new hair cells. As first step in determining the mechanism of hair cell regeneration, we developed an assay for cell divisions in the auditory epithelium after acoustic trauma. The results of these experiments demonstrate that supporting cells in damaged regions of the auditory epithelium incorporate the DNA-specific marker bromodeoxyuridine as early as one day after noise exposure. We provide direct evidence that following acoustic insult to the avian inner ear, supporting cells which reside within the sensory epithelium divide near the luminal surface and repopulate the epithelium. These results suggest that supporting cells participate in scar formation during hair cell degeneration, and produce new cells for regeneration.
\end{abstract}

\section{Introduction}

High intensity sounds can result in sensory cell (hair cell) loss in auditory epithelia, and subsequent hearing impairment (Saunders et al., 1985, 1991). In the organ of Corti (the mammalian auditory end-organ), nonsensory cells (supporting cells) replace lost hair cells, resulting in the construction of permanent scars (Bohne, 1976; Hawkins \& Johnson, 1981; Raphael \& Altschuler, 1991). These scars are associated with irreversible hearing deficit.

In contrast to the mammalian inner ear, hair cells in fish, amphibians and birds can regenerate after damage (Corwin, 1981; Corwin \& Cotanche, 1988; Ryals \& Rubel, 1988; Balak et al., 1990; Marsh et al., 1990). The source and nature of the signal for regeneration are not yet known. Identification of the source of new hair cells is a key factor in elucidating the mechanism of regeneration.

Generation of new hair cells in the lateral line organ of amphibians after experimentally-induced trauma occurs through divisions of supporting cells (Balak et al., 1990). Nevertheless, the source of new hair cells in regenerating avian inner ear has not been directly established. Indirect evidence suggests two different cell types as potential progenitors for repopulating damaged auditory epithelium: supporting cells within the sensory region (Corwin \& Cotanche, 1988) and epithelial cells which normally reside outside the sensory region (Girod et al., 1989).

The goal of the present study was to determine whether cell divisions occur within the sensory mosaic of acoustically injured avian auditory epithelium, and to identify the dividing cells. Chicks were exposed to intense noise and their auditory epithelia were analyzed for acoustic trauma. Bisbenzimide trihydrochloride (Hoechst), a DNA-specific label, was used to identify nuclei and dividing cells. Phalloidin labelling allowed for distinguishing hair cells from supporting cells (see Raphael, 1991). When applied together with Hoechst, phalloidin enabled us to determine the type of cells which divided. Bromodeoxyuridine (BrdU) administration prior to noise exposure was used to localize DNA synthesis, to determine the location of cell divisions and newly-divided cells. Scanning electron microscopy (SEM) and LM were used to assess the loss of hair cells and the responses of supporting cells. We show that supporting cells within the lesioned areas of the auditory epithelium divided and repopulated the auditory sensory mosaic after acoustic trauma. The results suggest that new hair cells may arise from supporting cell divisions.

\section{Materials and methods}

\section{Noise exposure}

Thirty-six one-week-old white Leghorn chick hatchings were used in the present experiments. Groups of six hatchlings were exposed to intense noise in a mesh-wire 
cage which was placed beneath a horn speaker. Exposure stimulus consisted of octave band noise with a center frequency of $1.5 \mathrm{kHz}$, presented at $120 \mathrm{~dB}$ SPL for $4 \mathrm{~h}$. Noise was generated by a random noise generator (General Radio Company, Model 1381), filtered by a variable filter (Model 2BR, Allison Labs) and amplified by a power amplifier (MC 2105, McIntosh). Sound intensity was measured with a Precision Sound Level Meter (Type 2203, Bruel \& Kjaer) at the onset and upon completion of each experiment.

\section{Tissue preparation}

Chicks were killed immediately following noise exposure or $24,36,48,72$, or $96 \mathrm{~h}$ after termination of noise exposure (six chicks were used for each time group). An additional 14 chicks were used as controls. Chicks were deeply anaesthe tized with Beuthanasia-D Special (Schering Corp., NJ) and perfused intracardially with $4 \%$ paraformaldehyde in $0.15 \mathrm{M}$ phosphate buffer at $\mathrm{pH}$ 7.4. They were decapitated after perfusion, the lower jaw removed, the head bisected in the mid-sagittal line and the inner ear region cut away from the skull with small scissors. Under stereoscopic magnification, skin, muscles and middle ear tissues were removed and the columella removed from the oval window. The remaining bone was peeled away to reveal the basilar papilla, and the auditory nerve was cut with iris scissors.

For whole-mount preparations, the tegmentum vasculosum was dissected free and the otoconial mass at the distal tip removed. The tectorial membrane was grasped with fine forceps at the distal part of the basilar papilla and removed. Removal of the tegmentum vasculosum and the tectorial membrane allowed en face analysis of the entire sensory region.

\section{Histo-and immunocytochemistry}

To localize DNA synthesis, BrdU (Sigma) (Gratzner, 1982) was systematically injected intraperitoneally, $125 \mathrm{mg} \mathrm{kg}^{-1}$, $10 \mathrm{~min}$ prior to noise exposure. Four unexposed controls were injected with BrdU and sacrificed $96 \mathrm{~h}$ later. To visualize BrdU, fixed tissue was immersed in the following solutions, with thorough rinsing between stages: $2 \mathrm{~N} \mathrm{HCl}$ in PBS with $0.15 \%$ Triton $X-100$ for $30 \mathrm{~min}, 5 \%$ normal rabbit serum, rat anti-BrdU antibody (Accurate Chemical, Westbury, NY) diluted 1:500 for $1 \mathrm{~h}$, rhodamine-conjugated rabbit anti-rat secondary antibody (Sigma) diluted 1:100 for $40 \mathrm{~min}$. Tissues were mounted in $60 \%$ glycerol in sodium carbonate buffer ( $\mathrm{pH}$ 8.5) with p-phenylenediamine. In control experiments, primary antibodies were eliminated.

Whole-mounts were labelled with fluorescent phalloidin to localize F-actin in the tissue. Tissues were permeabilized with $0.15 \%$ Triton $X-100$ for $5 \mathrm{~min}$, then incubated for $25 \mathrm{~min}$ in rhodamine phalloidin (Molecular Probes, OR) diluted 1:75 in PBS. Bisbenzimide trihydrochloride (Hoechst 33258 , Sigma), which binds specifically to DNA (Craig-Holmes \& Shaw, 1976), was used in conjunction with phalloidin to label all nuclei and mitotic chromosomes in the tissue. Tissues were immersed in $2 \mu \mathrm{g} \mathrm{ml}^{-1}$ Hoechst and rhodamine phalloidin (1:75) in PBS.

Preparations were analyzed using a Leitz Orthoplan microscope with $50 \times$ and $100 \times$ oil objectives. A rhodamine filter was used to visualize BrdU and phalloidin-specific staining. An UV filter was used to visualize Hoechst. Photography was performed using Kodak T-max 400 film exposed at 1600 ASA.

\section{Scanning electron microscopy and light microscopy}

Two left-side inner ears were processed for SEM in every survival-time group. Dissected specimens were immersed in $1 \%$ aqueous $\mathrm{OsO}_{4}$ for $30 \mathrm{~min}$, dehydrated in alcohol, critical point dried in $\mathrm{CO}_{2}$, sputter-coated with gold and examined in an AMRAY 1000B scanning electron microscope. Two right-side inner ears in every survival-time group were osmicated, dehydrated and embedded in Epon 812. One micron thick sections were obtained with glass knives, stained with Toluidine Blue and photographed with a Leitz Dialux microscope. Every tenth section in the area of lesion was collected and examined. When cells with mitotic chromosomes were identified, all consecutive sections were collected until dividing cells were completely sectioned.

\section{Results}

The distribution of phalloidin in control (unexposed) tissue revealed F-actin in stereocilia and the cuticular plate (terminal web) of hair cells, and in intercellular adherens junctions at the apical (luminal) region of the chick auditory epithelium, as previously described (Ginzberg \& Gilula, 1979; Raphael, 1991). This differential distribution of F-actin near the surface of the epithelial mosaic allowed us to distinguish between hair cells and supporting cells. Supporting cell tops appeared as narrow bars surrounding hair cells. In normal tissue, five or six supporting cells surrounded each hair cell, creating a pentagonal or hexagonal appearance at the apical surface of hair cells (Fig. 1A).

Twenty-four hours after noise exposure, lesions were observed approximately $1 \mathrm{~mm}$ from the proximal (high frequency) end of the basilar papilla. The

Fig. 1. En face view of whole-mounts of chick basilar papilla using fluorescent light microscopy with phalloidin label (A, B, D) or SEM (C). (A) The apical surface of the auditory epithelium in control (unexposed) basilar papilla is a mosaic composed of hair cells and supporting cells. F-actin-specific label is found in stereocilia (s) and cuticular plate (c) of hair cells and in the intercellular adherens junctions (arrow). Hair cells are pentagonal or hexagonal. Each side of the polygon is bordered by the apical surface of a supporting cell. (B) Twenty-four hours after noise exposure, the apical surface of supporting cells appears expanded and many hair cells are missing. Surviving hair cells display damaged stereocilia. (C) Hair cells were completely absent in one region $36 \mathrm{~h}$ after noise exposure. The area was covered by scars made by supporting cells. (D) The distribution of F-actin in intercellular junctions $36 \mathrm{~h}$ after noise exposure reveals cy toarchitecture similar to SEM image, with total absence of hair cells. Confluent scar tissue covers the epithelial surface. Scale bar $=5 \mu \mathrm{m}$. 


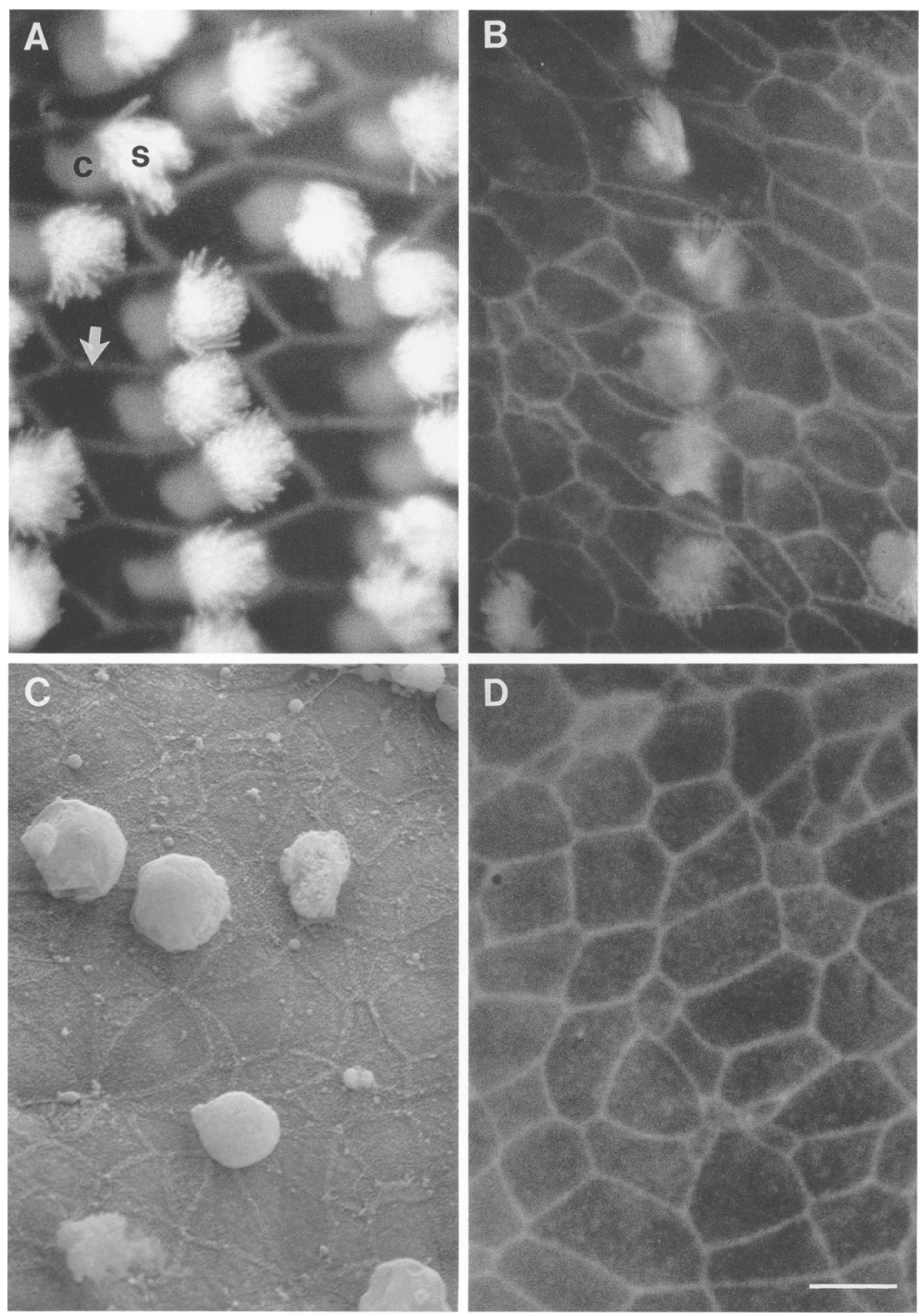




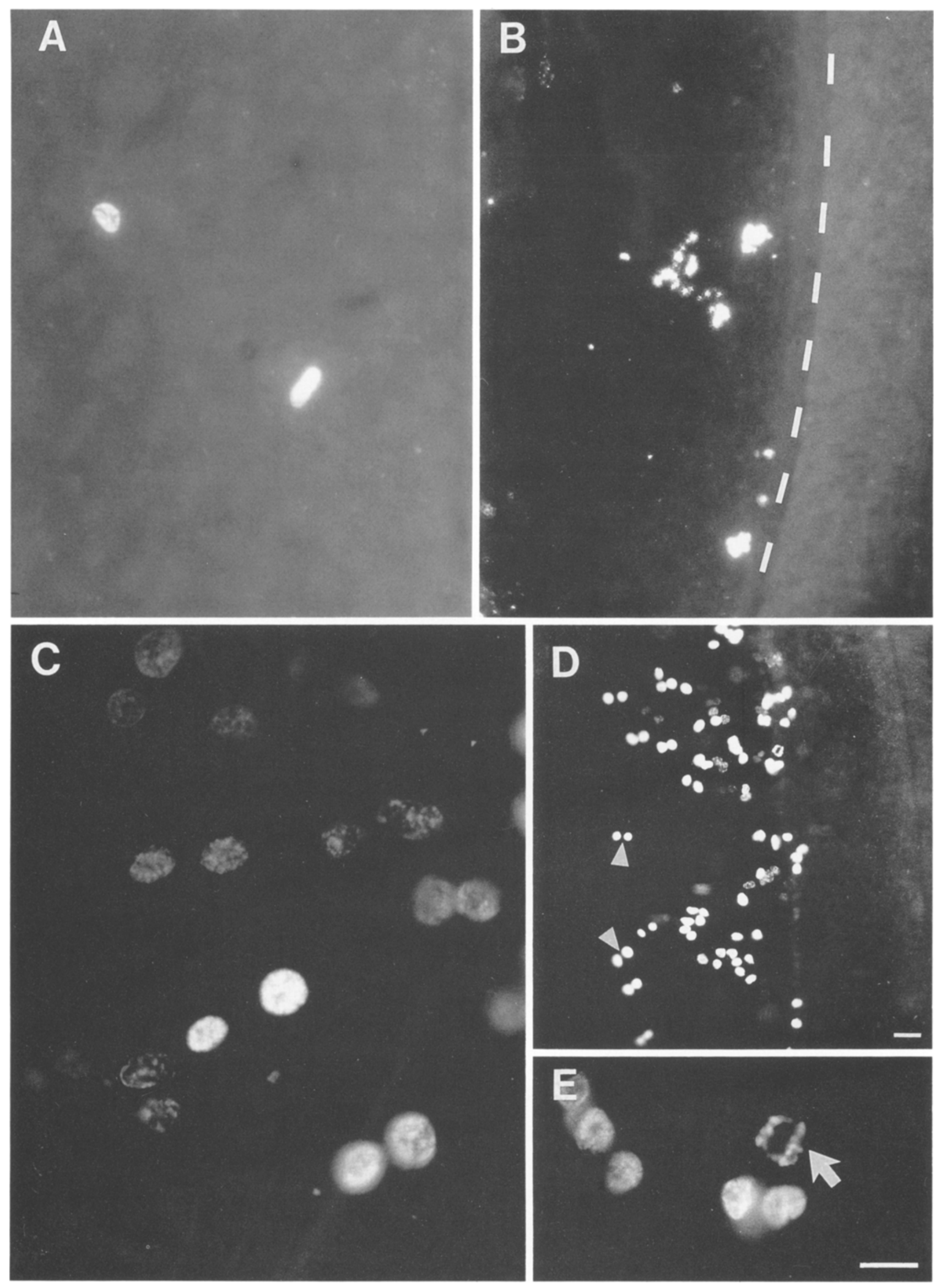

Fig. 2. En face view of chick basilar papilla labelled for BrdU. (A) Twenty-four hours after noise exposure BrdU-labelled nuclei are found in the basilar papilla. (B) Low magnification analysis shows that the distribution of BrdU-labelled nuclei $24 \mathrm{~h}$ after the noise was restricted to the basilar papilla (the area left of the border line). (C) Thirty-six hours after noise exposure, BrdU-labelled nuclei are present in the lesion in the basilar papilla at a focal plane immediately beneath the luminal surface. (D) Low magnification micrograph reveals the distribution of BrdU-labelled nuclei (most of them are in pairs, arrow-heads) in the basilar papilla. The location and orientation in the tissue and the focal plane were determined using phase contrast optics. (E) Mitotic chromosomes in anaphase (arrow) 36 h after noise exposure immediately beneath the luminal surface. Scale bars: $10 \mu \mathrm{m}$; bar in (D) for (B) and (D), bar in (E) for (A), (C) and (E). 
distribution of F-actin in the lesions revealed a severe hair cell loss (Fig. 1B). Scanning electron microscopical analysis $36 \mathrm{~h}$ after noise exposure revealed a lesion with extensive hair cell loss. Expanded supporting cells resided in spaces normally occupied by hair cells (Fig. 1C). The distribution of F-actin in intercellular adherens junctions (Fig. 1D) confirmed the surface analysis with SEM. Both SEM and fluorescence microscopy revealed a continuous reticular lamina at all stages examined (Fig. 1C, D).

Fluorescence immunocytochemistry with BrdUspecific antibodies was used to localize BrdU-labelled nuclei. In control (unexposed) auditory epithelia, no labelled cells were detected in the sensory area $96 \mathrm{~h}$ after BrdU injection; however, blood vessels and cartilage cells near the basilar papilla contained several labelled nuclei, showing that injected BrdU was taken up, distributed in tissues and incorporated into cell types which continually divide (data not shown). In noise-exposed chicks, BrdU-positive nuclei were detected in the sensory mosaic at the site of lesion as early as $24 \mathrm{~h}$ following noise exposure (Fig. 2A,B). Using phase contrast microscopy, it was determined that BrdU-positive nuclei were located at various focal planes at this stage, between the basal end of the epithelium (near the basilar membrane) and the apical region (near the luminal border). Thirty-six hours after noise exposure, the number of BrdU-labelled nuclei observed in the lesion was increased and many nuclei appeared in pairs, located immediately beneath the luminal border (reticular lamina) of the sensory mosaic (Fig. 2C,D). Some BrdU-labelled mitotic chromosomes were also present (Fig. 2E). In some cases, A small number of BrdU-labelled nuclei were also observed in non-sensory areas adjacent to the basilar papilla $36 \mathrm{~h}$ after noise exposure. In animals allowed to survive $96 \mathrm{~h}$ after noise exposure, most BrdU-labelled nuclei were arranged in pairs located immediately beneath the reticular lamina (results not shown).

En face analysis of Hoechst-labelled whole-mounts enabled us to visualize nuclei in the entire auditory epithelium, including the area of hyalin and cuboidal cells outside the sensory region. In control tissue, hair cell nuclei resided immediately beneath the luminal border of the auditory epithelium, whereas nuclei of supporting cells were detected at a lower focal plane (results not shown). Fluorescence microscopy of tissues labelled with Hoechst and phalloidin enabled us to identify all nuclei in the tissue and distinguish hair cells from supporting cells at the level close to the luminal border (Fig. 3). Thirty-six hours after noise exposure, several damaged hair cells were visible in the lesion and supporting cells with expanded apical surfaces occupied the spaces of missing hair cells (Fig. 3A). Hoechst label clearly revealed nuclei and mitotic chromosomes in the lesion (Fig. 3B). The distribution of F-actin in cells which contained Hoechst-labelled mitotic chromosomes revealed that dividing cells within the lesion were invariably supporting cells (Fig. 3A,B). Dividing cells were detected in areas where no hair cells remained, as well as where some surviving hair cells were present. Hoechst label showed dividing cells in different stages of mitosis (Fig. 3B-D). In all stages of mitosis, chromosomes were positioned in a focal plane immediately below the luminal surface of the lesion.

Light microscopical analysis of serial cross-sections enabled us to determine the shape of dividing supporting cells. Supporting cells containing mitotic chromosomes $36 \mathrm{~h}$ after noise exposure appeared spherical in shape and contacted the luminal surface but not the basal lamina. Cells in anaphase contained a mitotic spindle which was oriented in a plane parallel to the luminal surface (Fig. 4A).

Small, immature hair cells were observed in the lesion $96 \mathrm{~h}$ after noise exposure (Fig. 4B). Apical cell perimenter and length of stereocilia were the criteria used to determine the degree of differentiation of young hair cells. According to these criteria, many young hair cells appeared in pairs. The two cells in each pair were of similar size, had stereocilia of similar length, and could be distinguished from neighbouring pairs with different dimensions (Fig. 4C). At the stage when young hair cells could be detected with SEM, the young cells were polarized and their kinocilia were aligned approximately in register with other cells in the basilar papilla. In all specimens examined, the reticular lamina appeared confluent.

\section{Discussion}

The results of these experiments demonstrate that a

Fig. 3. En face view of whole-mounts of chick basilar papilla lesion $36 \mathrm{~h}$ after noise exposure, showing the lesioned area labelled for F-actin (A) and Hoechst (B-D). (A) The preparation is double-labelled with phalloidin and Hoechst (shown in (B)). Viewing through the rhodamine filter (in $(A)$ ), several surviving hair cells are seen, surrounded by expanded supporting cells. (B) The same field shown in (A) viewed through the ultraviolet filter reveals Hoechst label at a focal plane immediately beneath the luminal surface of the epithelium. Hoechst label is found in DNA of nuclei at this focal plane and in chromosomes of one dividing cell in metaphase (arrow). The dividing cell is identified as a supporting cell by the distribution of phalloidin (arrow in (A), pointing to the same area as arrow in (B)). (C) Hoechst-labelled dividing cell in anaphase at a focal plane parallel to and immediately below the luminal surface of the lesion. (D) A dividing cell in telophase completing the mitosis at a plane parallel to the luminal surface. Scale bars $=5 \mu \mathrm{m}$. 

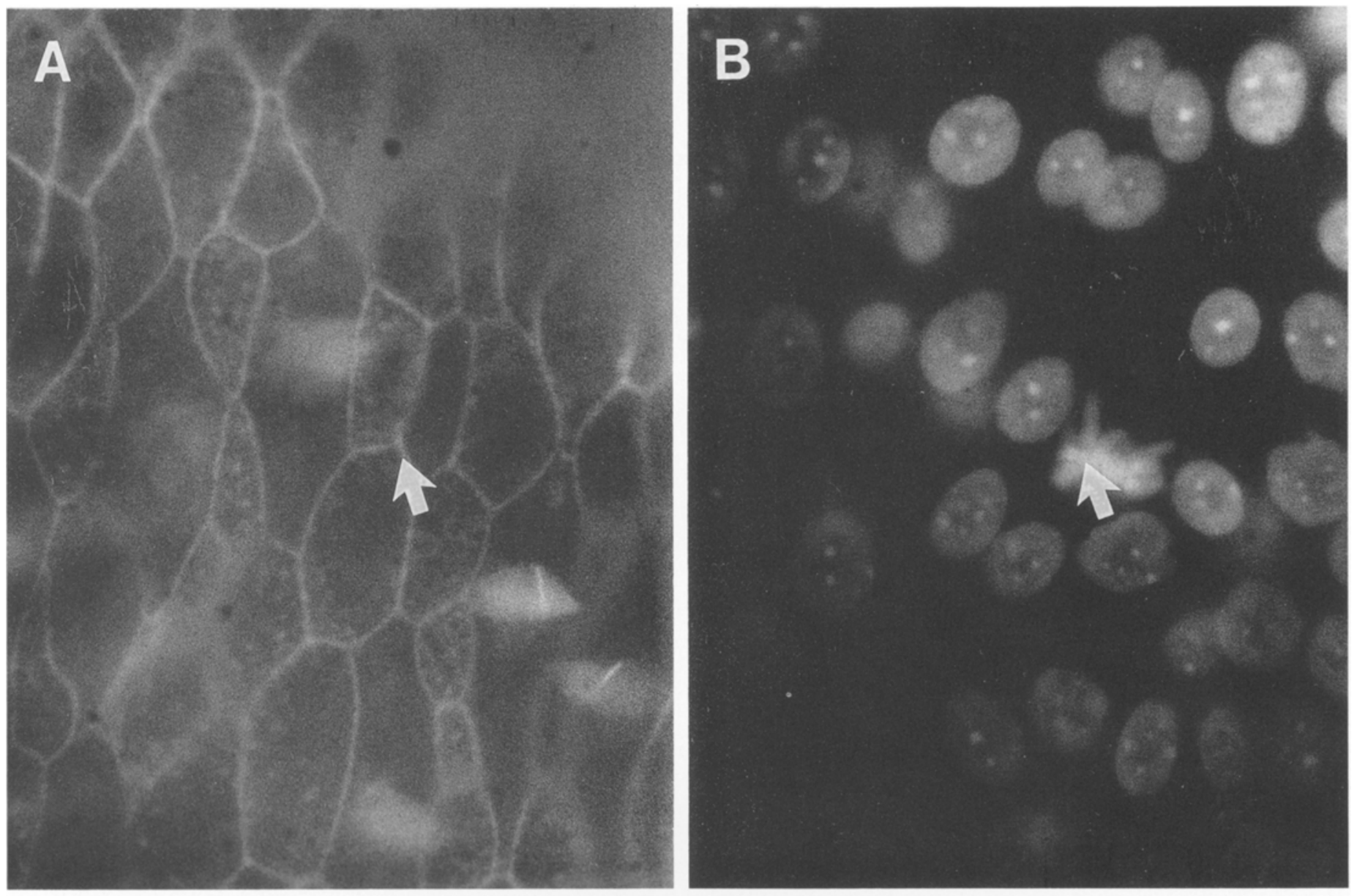

C

D 

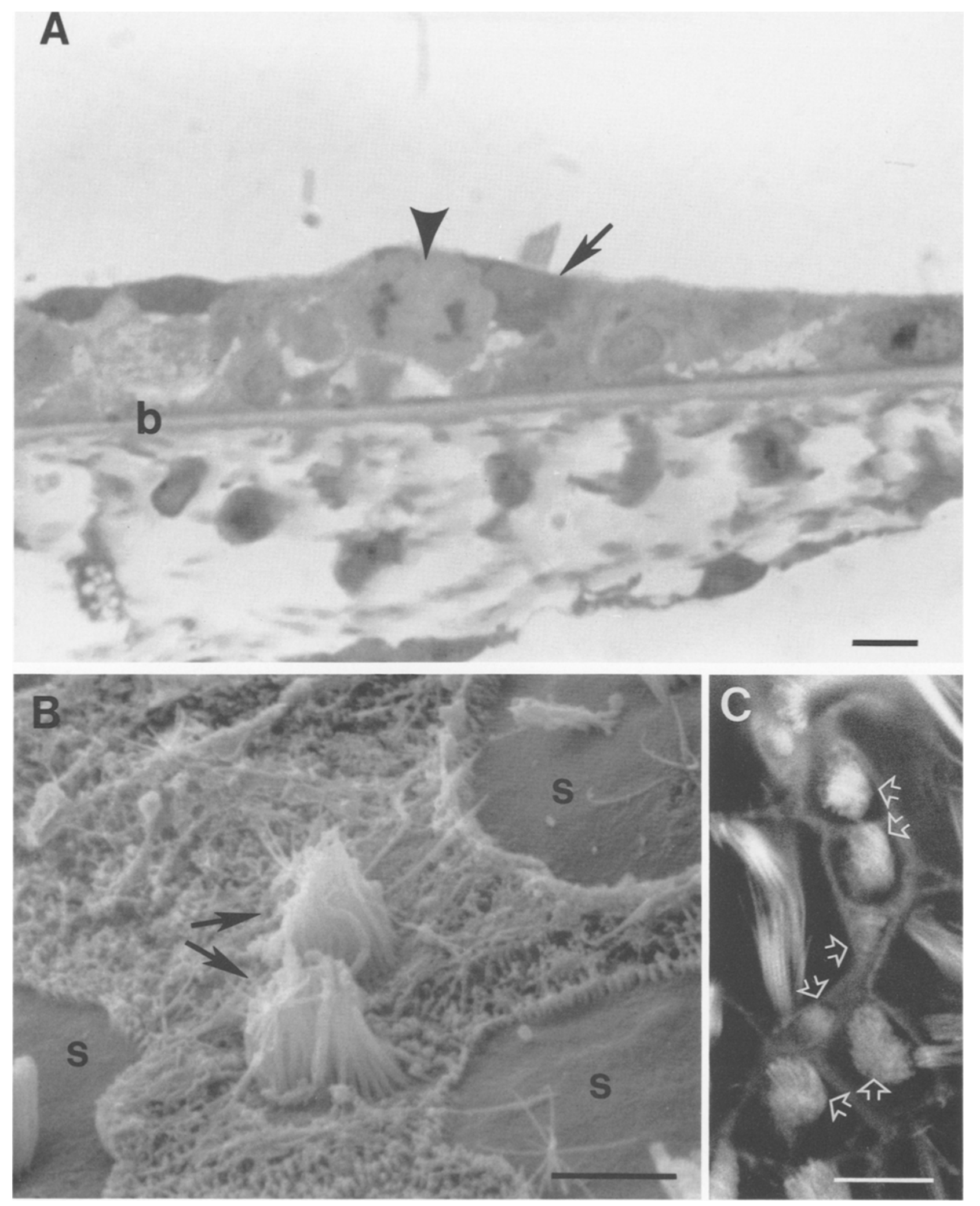

Fig. 4. Cross-section through the lesion $36 \mathrm{~h}$ after noise exposure (A), SEM view $96 \mathrm{~h}$ after noise exposure (B) and F-actin distribution $96 \mathrm{~h}$ after noise exposure (C). (A) Several hair cells (dark cytoplasm) and supporting cells populate the basilar papilla in the lesion (b, basal lamina). Near one hair cell (arrow) a supporting cell is in late anaphase (arrowhead). This dividing cell is round and its apical pole has luminal contact. The basal pole has no contact with the basal lamina. (B) Apical surface of three damaged hair cells which survived the trauma (s) seen among scar tissue made by supporting cells (microvilli-covered area). Two immature hair cells (arrows) are seen in scar area. Size of stereocilia and stage of differentiation are similar in the pair of young cells. Note that kinocilia in both cells are in same pole. (C) F-actin distribution in the lesion reveals intercellular junctions and stereocilia. Small and immature hair cells are located among damaged cells. Based on size of apical surface and degree of stereocilia differentiation, adjacent immature cells reside in pairs (open arrows point at three pairs of young hair cells). Scale bars $=5 \mu \mathrm{m}(\mathrm{A}, \mathrm{C}), 2 \mu \mathrm{m}$ (B). 
four-hour exposure to noise is sufficient to cause hair cell loss and mitotic activity in supporting cells within the lesioned sensory mosaic.

Previous studies have demonstrated that regenerated hair cells in avian auditory epithelium incorporated tritiated thymidine, suggesting that these cells arise from divisions (Corwin \& Cotanche, 1988; Ryals \& Rubel, 1988). However, dividing cells could not be identified and therefore the identity of the precursor cells and the site of divisions remained a matter of controversy. In the present study, we report the presence of mitotic chromosomes in cells within the basilar papilla $36 \mathrm{~h}$ after trauma. Dividing cells had luminal contact and appeared either adjacent to surviving hair cells or in areas with total absence of hair cells. Since supporting cells are the only non-sensory cell type in the basilar papilla, the results indicate that supporting cells within the auditory sensory mosaic can be induced to divide by exposure to intense noise.

Dividing cells were observed in acousticallylesioned areas of chick auditory epithelium as early as one day after noise exposure. In contrast, no dividing cells and no BrdU-labelled cells were found in the sensory mosaic of control (unexposed) chicks. These results indicate that proliferative activity was induced by the acoustic trauma. The data further confirm the observation that spontaneous turnover in the sensory mosaic of the avian auditory epithelium is either absent or extremely rare (Corwin \& Warchol, 1991).

Girod and colleagues (1989) have suggested that cell migration from areas adjacent to the sensory mosaic accounts for cell renewal in the lesion. In the present experiments, which used a relatively short noise exposure and resulted in a limited and confined lesion, mitotic activity in the sensory areas was earlier and much more significant in quantity, as compared with non-sensory areas. The present results indicate that cell divisions within the sensory mosaic serve to repopulate the damaged auditory epithelium. The data presented here are consistent with reports that supporting cell division occurs following hair cell ablation in salamander lateral line, and that supporting cells proliferate during postembryonic life in fish and amphibians (Balaket al., 1990; Corwin \& Warchol, 1991). It is possible, however, that very extensive lesions in the auditory epithelium, which include damage to supporting cells, may result in migration of other cells into the lesion.

Supporting cells appear to play significant roles in maintenance of the tissue after trauma. During scar formation, supporting cells expand and replace degenerated hair cells in chick (Cotanche \& Dopyera, 1990; Marsh et al., 1990; Raphael \& Altschuler, 1992) and mammal (Bohne, 1976; Raphael \& Altschuler, 1991). Supporting cells can replace damaged hair cells while maintaining the structural continuity of the luminal (apical) border in mammal (Forge, 1985; Raphael \& Altschuler, 1991) and chick (Raphael \& Altschuler, 1992). In the present experiments, the structural integrity of the reticular lamina was maintained at all stages examined, suggesting that scar formation and supporting cell division may occur without disrupting the continuity of the reticular lamina. Our experiments showed that cell divisions occurred in areas where no hair cells remained as well as in areas where surviving hair cells were present. It appears, therefore, that initial stages of repopulating the auditory epithelium can occur in the absence of proximity to hair cells. Future experiments are necessary to determine whether supporting cells play a role in orienting new hair cells.

The results of this study demonstrate supporting cell mitosis in the luminal surface of the avian auditory epithelium. This pattern of proliferative activity is similar to that seen in simple epithelia, where nuclei migrate towards the basal lamina during S-phase and then ascend to the luminal surface for division (Sauer, 1935). At the time when BrdU-labelled nuclei were first detected ( $24 \mathrm{~h}$ after the noise exposure), they were located at various heights in the epithelium, between the apical and basal borders. This suggests that interkinetic migration of nuclei (Sauer, 1935) occurs during regeneration of the chick basilar papilla.

In the current study, BrdU-labelled nuclei and newly formed hair cells in regenerating basilar papillae appeared in pairs. These observations suggest that pairs of new hair cells may result from transdifferentiation of pairs of newly divided supporting cells. This distribution of daughter cells is similar to that seen in fish lateral line, where newly generated hair cells also appear in pairs (Rouse \& Pickles, 1991).

We have demonstrated that supporting cell divisions serve to repopulate the traumatized avian auditory epithelium. Further studies will help determine whether scar formation is a prerequisite for initiation of supporting cell division, and whether new hair cells arise from transdifferentiation of supporting cells.

\section{Acknowledgements}

I would like to thank Michael $K$. Lee for skilful assistance in specimen preparation. I would also like to thank Linda Gaffney and Exic Wolf for printing the micrographs. I greatly appreciate the contribution of Richard A. Altschuler, Thomas E. Carey, Peter F. Hitchcock, Donna M. Martin and Pamela A. Raymond, who provided valuable suggestions and criticism of this manuscript. This work was supported by a grant from the Deafness Research Foundation. 


\section{References}

BALAK, K. J., CORWIN, J. T. \& JONES, J. E. (1990) Regenerated hair cells can originate from supporting cell progeny: evidence from phototoxicity and laser ablation experiments in the lateral line system. Journal of Neuroscience $\mathbf{1 0}$, 2502-12.

BOHNE, B. A. (1976) Healing of the noise damaged inner ear. In Hearing and Davis: Essays Honoring Hallowel Davis (edited by HIRSH, S. K., ELDREDGE, D. H., HIRSH, I. J. \& SILVERMAN, S. R. ) pp. 85-96. Saint Louis: Washington University Press.

CORWIN, J. T. (1981) Postembryonic production and aging of inner ear hair cells in sharks. Journal of Comparative Neurology 201,541-53.

CORWIN, J. T. \& COTANCHE, D. A. (1988) Regeneration of sensory hair cells after acoustic trauma. Science 240 , $1772-4$.

CORWIN, J. T. \& WARCHOL, M. E. (1991) Auditory hair cells: structure, function, development, and regeneration. Annual Reviews in Neuroscience 14, 301-33.

COTANCHE, D. A. \& DOPYERA, C. E. J. (1990) Hair cell and supporting cells response to acoustic trauma in the chick cochlea. Hearing Research 46, 29-40.

CRAIG-HOLMES, A. P. \& SHAW, M. W. (1976) Cell cycle analysis in asynchronous cultures using the BrdUHoechst technique. Experimental Cell Research 99, 79-87.

FORGE, A. (1985) Outer hair cell loss and supporting cell expansion following chronic gentamicin treatment. Hearing Research 19, 171-82.

GINZBERG, D. R. \& GILULA, B. N. (1979) Modulation of cell junctions during differentiation of the chicken otocyst sensory epithelium. Developmental Biology 68, 110-29.

GIROD, D. A., DUCKERT, L. G. \& RUBEL, E. W. (1989) Possible precursors of regenerated hair cells in the avian cochlea following acoustic trauma. Hearing Research 42, 175--94.

GRATZNER, H. G. (1982) Monoclonal antibody to 5-bromo and 5-iododeoxy-uridine: a new reagent for detection of DNA replication. Science $218,474-5$.
HAWKINS, J. E. JR \& JOHNSON, L.-G. (1981) Histopathology of cochlear and vestibular ototoxicity in laboratory animals. In Aminoglycoside Ototoxicity (edited by LERNER, S. A., MATZ, J. G. HAWKINS, J. E., IR) pp, 175-95. Boston: Little, Brown and Company.

MARSH, R. R., XU, L., MOY, J. P. \& SAUNDERS, J. C. (1990) Recovery of the basilar papilla following intense sound exposure in the chick. Hearing Research 46, 229-38.

RAPHAEL, Y. (1991) Damage to the tectorial membrane may protect chick hair cells from noise overstimulation. Hearing Research 53, 173-84.

RAPHAEL, Y. \& ALTSCHULER, R. A. (1991) Modulation of cytoskeletal and junctional proteins during hair cell degeneration. Cell Motility and the Cytoskeleton 18, 215-27.

RAPHAEL, Y, ALTSCHULER, R. A. (1992) Early microfilament reorganization in injured auditory epithelia. Experimental Neurology 115, 32-6.

ROUSE, G. W. \& PICKLES, J. O. (1991) Paired development of hair cell in the neuromasts of the teleost lateral line. Proceedings of the Royal Society of London (Series B) 246 , 123-8.

RUBEN, R. J. (1967) Development of the inner ear of the mouse: a radioautographic study of terminal mitoses. Acta Oto-laryngologica (Suppl) 220, 1-44.

RYALS, B. M. \& RUBEL, E. W. (1988) Hair cell regeneration after acoustic trauma in adult Coturnix quail. Science 240, $1774-6$.

SAUER, F. C. (1935) Mitosis in the neural tube. Joumal of Comparatioe Neurology 62, 377-405.

SAUNDERS, J. C., DEAR, S. P. \& SCHNEIDER, M. E. (1985) The anatomical consequences of acoustic injury: a review and tutorial. Joumal of the Acoustical Society of America 78, $833-60$

SAUNDERS, J. C., COHEN, Y. E. \& SZYMKO, Y. M. (1991) The structural and functional consequences of acoustic injury in the cochlea and peripheral auditory system: a five year update. Joumal of the Acoustical Society of America 90, 136-46. 